\title{
A Total Cost of Operation (TCOp) Analysis of Electric Vehicles Introduction in Urban Transport in La Havana.
}

\author{
Jorge Marciano Rodríguez Matienzo ${ }^{1}$ \\ http://orcid.org/0000-0002-5015-1195 \\ ${ }^{1}$ Technological University of La Havana, La Havana, Cuba. \\ Editor-in-Chief: Alexandre Rasi Aoki \\ Associate Editor: Alexandre Rasi Aoki
}

Received: 2021.05.05; Accepted: 2021.06.07.

*Correspondence: matienzo@mecanica.cujae.edu.cu; jrmatienzo55@gmail.com. Tel.: +53-53325386 (J.M.R.M.).

\section{HIGHLIGHTS}

- An expression to relate the EV range by EPA with range by NEDC or WLTP was obtained.

- Small EV needs subsidies or battery leasing to compete with an ICE car in the private sector.

- EV are more competitive respect an ICEV as the distance traveled is larger.

\begin{abstract}
The urban transport electrification is going upward in many countries. However, this electrification faces many hurdles, among them, the limited range and cost that present-day electric vehicles (EV) have. This paper analyzes which Battery Electric Vehicles (BEV) could meet the current car travel needs in different uses. The results from a survey about distance travelled in daily trips in La Havana, allow the assessment of maximum average daily distance travel (MADT) by the private owners, cars in public service, taxis and leasing. The Lognormal distribution adjusts to MADT's histogram in each group, and yields estimates characterizing its behavior. The use of a database of BEV with more than 60 electric vehicles allows to select an appropriate model for each use. The BEV's range is normally expressed using several driving cycles, being EPA (Environmental Protection Agency) the most adequate, but the range by EPA is not always available. A regression analysis was made to obtain the EPA range as a function of range by others driving cycles. Finally, a Total Cost of Operation (TCOp) is calculated considering the purchase cost, energy cost, maintenance, etc. The outcomes are that for the private use, only small BEV with a strong subsidy or battery leasing can compete with an Internal Combustion Engine Vehicle (ICEV). In the public, taxis and leasing sector, the BEV are competitive in several years. The daily mileage and electricity cost are decisive. The use of renewable energy to charge batteries can reduce this period to some extent.
\end{abstract}

Keywords: Battery Electric Vehicle; total cost of operation; BEV range.

\section{INTRODUCTION}

The world is moving to electric mobility with a steady resolution. The global electric car fleet reached 7,2 million (M) in 2018, 6\% more than in 2019. China is the leader, with 47\%, nine countries have more than 100 000 units on the road [1]. Several countries have a clear policy on this subject, Norway is heading the EV national sales in the world by percentage, and in $2019,46 \%$ of total automobile sales in Norway were electric. In the next 5 years more than 200 new models will be available, according to automakers news. Nevertheless, 
most of the vehicles today are vehicles with an Internal Combustion Engine (ICE). Only with the oil crisis in 1970 , some governments looked back to electric mobility as a solution: the change in automobile prime mover is the key factor in the answer to fossil fuel dependence and reduction of pollution and GHG emissions.

In Cuba, the situation is very similar. The environmental pollution is not yet a big problem, but some urban zones have some worrying level. In 2017, 7248,8 million of Tons (MT) of oil and derivatives were consumed, from this, 1648,3 of gasoil, 262,3 of gasoline and 4766 of fuel. Gasoil and gasoline are used mainly in transport, representing a 26,3\% from the total. The ground transport (including gasoil and gasoline) required $710,3 \mathrm{MT}(43 \%)$. In the same year were consumed $177 \mathrm{MT}$ of gasoline in transport, from this quantity 97,5 MT by private owners (37\% from the total, $54 \%$ from the total used in ground transport),[2].

In volume, these numbers represent $883,3 \times 10^{6}$ liters of gasoil and $260,3 \times 10^{6}$ liters of gasoline. Considering a final price of 1,01 USD/L for gasoil, and 1,09 USD/L for gasoline [3], this represents an expenditure of 862 and 283 MUSD respectively, 1145 MUSD in total. Moreover, if the efficiency of a vehicle with ICE is included in the equation, taking for example an optimistic value of $17 \%$, so around 884 MUSD were wasted moving persons and load using conventional vehicles.

The economic burden this represents for the country is evident. Moreover, in the same year, 1378 MT of gasoil and 168,8 MT of gasoline were imported, a $64 \%$ of total the gasoline consumed, which represents a risky dependence of external sources. Concerning composition of the Cuban vehicle fleet, in 2017 there were 634685 vehicles. From this total, around 280000 are light vehicles, 57000 are vehicles in public service, the rest belongs to private owners. There are also 19000 buses, mostly of them in public service. La Havana, capital of the country, has a $32 \%$ from the total of vehicles. The average fleet age is around $25-$ 30 years, with more than $60 \%$ above 20 years [4].

Summing up, the country has an aged vehicle fleet, with a high dependence of external sources fuel, and the same financial problems common to any other third world country. And last, but not least, the country has an important potential and experience in the use of photovoltaic energy because of its geographical position; this could be the solution in achieving a fuel independence, in the case of a massive electric mobility.

The main concern related with the use of electric vehicles is the distance one can travel with a full charge. In the case of a hybrid electric vehicle (HEV), this is not of such importance, because of the presence of an ICE to recharge batteries. Nevertheless, this implies the use of some amount of petrol. In Cuba, however, the focus is on BEV; but the use of HEV or even the use in certain proportion of conventional cars should be always considered. All types of automobile have a role to play in every transportation scheme, whatever it is.

Another factor is the cost efficiency of an EV compared to an ICEV. Many authors ensure that the fact of the higher efficiency of the EV over an ICEV as a decisive feature, but there are other aspects to consider, like its elevated price and cost in charging infrastructure that should be evaluated.

The determination of the suitable range of a BEV is of paramount importance. Range is not only related with the foreseeable autonomy and consequent performance of the $\mathrm{EV}$, range has a strong link with battery capacity and with car price. An underestimation of the necessary range leads to a fail in fulfilling BEV functions, forces the driver to change his driving patterns; an overestimation leads to unnecessary high payments in battery, with economic consequences. Another undesirable effect of range underestimation is the so-called range anxiety, a driver feeling (real or not) that he will not reach his destination. This range anxiety can produce confusion and loss of attention, and even accidents. In any case, EV needs to be operationally suitable for the task that they are required to perform.

In this paper, the answer to these questions will be searched. Knowledge about light vehicles driving patterns is primordial for a possible introduction of BEV. There is no previous study about urban traffic behavior in La Havana. The way selected to obtain information was a survey and a personal interview, which also included questions about the fuel consumption, expenses in maintenance, etc. The cost efficiency is evaluated using a Total Cost of Operation toll.

Several authors have dealt with the determination of necessary range for a BEV, mainly from the point of view of BEV market adaptation to customers' preferences.

Mellinger and coauthors [5] investigated the influence of charging facilities. They define a "BEV potential" as the portion of trips that can be made by a BEV, given the availability of charging possibilities. Results show that almost $86 \%$ of trips can be done without problems with a BEV in the present market. This is consistent with Needell and coauthors [6]. Data collected by GPS devices were used to evaluate the potential of using the 2013 Nissan Leaf (115 km range] to cover personal travels in several US cities. More than $87 \%$ of trips can be covered without a midway charging.

Shi and coauthors [7] approached to the question of Minimum Range Required for a BEV. The result shows a difference between taxis and private vehicles; for taxis, the optimal range is between 100 to 200 
miles. Private vehicles require a lower range, $40 \%$ can operate below 50 miles, and $77 \%$ can use current technology. In all cases, it is supposed the possibility of using charging station during parking time.

Franke and Krems [8], analyze a sample of 80 BEV drivers in Germany, who accepted to install a charge station at home. The results shows a difference between owners range preference and range needed, usually the first one is bigger. According to drivers, preferences are in an interval of 135,9 to $144,9 \mathrm{~km}$, but $80 \%$ of drivers travel as a maximum $60 \mathrm{~km}$ distance per week, $80 \%$ prefer a minimum range of $160 \mathrm{~km}$.

Dimitropoulos and coauthors [9] performed a meta-analysis of more than 80 studies on consumer causes for not to buy an ICEV. They found that, as a rule, consumers are less eager to pay for a BEV when its range increases; a BEV with a range up to 100 miles appears to be the favorite one.

Yuan $Q$ and coauthors [10] conducted a research in China to study the influence of different factors on range anxiety, using data from a sample of Chinese BEV drivers. It is interesting that $55 \%$ of drivers used to charge at home and an $18 \%$ has a portable charger on the trunk. They define a "safety buffer" as the period in $\mathrm{km}$ from the beginning of range anxiety to the moment when this interferes with the driver's behavior. As an average, the safety buffer is around $25 \%$ of trip distance. The information about the battery SoC (State of Charge), and the remaining distance the car can travel is important to reduce range anxiety.

Pearre and coauthors [11] analyzed the daily driving pattern of 484 gasoline cars in more than 50 days. From the study, it follows that in the vast majority of days, daily trip extension is below 100 miles, and even most of the trips are below 50 miles. Only in 23 days per year, the distance travelled is over 100 miles and requires an adaptation, for example, to recharge before destination.

A deeper understanding is possible if a Probability Density Function (PDF) is fitted to data of travelled distance. The use of a PDF allows making predictions with more precision. Plötz and coauthors [12] studied 4 data sets on conventional car movement, they define the variable VKT, "Vehicle Kilometer Travelled". Histograms of VKT per day are peaked and skewed, they tested two parameters PDF goodness of fit and the result was that the Lognormal PDF fit to VKT better than a Weibull or Gamma distributions.

Most of the research done in this field uses individual daily travelled distance as variable (VKT). This criterion can underestimate the range needs, a vehicle that can make an average daily range may not cover user needs in some days. Pearre and coauthors [11] used "maximum daily travelled distance", Bastian and coauthors [13] propose the same, but per week. This gives a representation of the worst day, and is better for analysis of limited range vehicles, as BEV.

Yang and coauthors [14] used the average of daily VKT from a sample of 50 BEV in a year. From the study, it follows that the average VKT is around $50,7 \mathrm{~km}$, average distance between charges is $49,5 \mathrm{~km}$. The average travelled distances are well below vehicle range, and the average distance between charges is below average VKT, the average SoC before charge was $45 \%$ and most of all charges were almost until full charge. This shows a very conservative use of BEV: drivers prefer to charge battery whenever it is possible, more than $34 \%$ of charges were done during daytime in stations of $3,8 \mathrm{~kW}$. This study shows that driver criteria are decisive in the use of vehicle range and that the supposition of preference for night charge is very fragile.

The issue of cost efficiency is presented by Lebeau and coauthors [15]; using a TCO (Total Cost of Ownership) model. The result depends on car segment and battery size: in small and medium cars, only with battery leasing an EV is most attractive than an ICEV. They assume a group of cost applied in Europe, including a very high value in maintenance (65\% of maintenance cost of a similar ICE vehicle).

Breetza and Salon [16] address the influence of cost and policy in BEV adoption. They consider a faster depreciation rate for a BEV than for an ICEV, shorter periods of ownership, etc. Subsidies and gasoline prices have a strong influence together with charging possibilities.

Logtenberg and coauthors [17], present the result of a study in Canada in 2018. They assume 10 years and $250000 \mathrm{~km}$ as the period for evaluation of BEV and ICEV. Result shows a BEV cost in fuel and maintenance of $20 \%$ and $52 \%$ per year over a similar ICEV. Saving in maintenance is around 5500 USD, and in fuel, almost 22000 , both in 10 years. A change in battery is not included in maintenance.

Raustad, [18], compared the total life cycle costs of different models of EV, and ICEV. Outcomes are the following: in 5 years, a Nissan Leaf annual cost is 5360 USD per year, and a Hyundai Elantra, 7076 . In 10 years the Leaf cost 4 683/year and the Hyundai at 6 040/year. The most influencing factor is the lower cost of electricity compared to petrol. In the report, the battery price is obtained by an empiric equation, battery kWh price is estimated in 180 USD in 2030; all is based on simulations.

Pröpfe and coauthors [19] analyze the cost competitiveness of different EV in Germany, using a TCO analysis during 4 years or $40000 \mathrm{~km}$. Maintenance and repair cost of BEV are estimated in $€ 0,06 / \mathrm{km}$ and for ICEV in $€ 0,072 / \mathrm{km}$. According to authors, the battery life is around $489000 \mathrm{~km}$ in BEV. Results indicate that no single type of EV is the most suitable to replace an ICEV. 
In general, the current BEV's battery technology and range are considered enough to satisfy range needs of ICEV's drivers in a significant percent, the average daily VKT varies from one country to another. Normally, the drivers' preferences on range are overvalued, the range anxiety is a key factor in this behavior. Driver will charge batteries when they have an opportunity, even in daytime, if a charge station is available, no matter if they have charged at home during nighttime. Moreover, they will always try to charge until $100 \%$. The charging station network is crucial in order to obtain acceptation of electric mobility.

About the cost efficiency, the national conditions are very important, the fuel and electricity prices varies in each country, the vehicle real life is also different, and the influence of maintenance cost is variable. Alexander and coauthors [20] consider the maintenance cost of an EV as 61\% over an ICEV and Pröpfe and coauthors [19] estimate a 49\%. The experience in Cuba is limited, but the experts' criteria are that expenses in maintenance are very low compared to a similar ICEV. At the time this paper is written, with almost 4 years of BEV and HEV in operation in Cuba, only minor bodywork, and revision in suspension and steering system have been executed. Likely, the values mentioned from others countries are relatively high due mainly to labor time prices in some nations.

\section{MATERIAL AND METHODS}

The data on distance travelled was obtained from a survey made to a sample of car owners and drivers, cars were classified in four groups according to car use: Private (only private owners), Public (only from public services), Taxis (taxis, both private and public) and Leasing (used normally in commercial activities). Details of each group are in Table 1. Information was gathered in La Havana in the last months of 2019; each driver was questioned about the longest travel per week he made over one month; and the MADT is defined as its average value.

Table 1. Sample composition.

\begin{tabular}{lllll}
\hline & Quantity & Average age (years) & Petrol & Diesel \\
\hline Total & 376 & 23,1 & 256 & 120 \\
Private & 97 & 35,7 & 87 & 10 \\
Public & 212 & 17,4 & 102 & 110 \\
Taxis & 17 & 33,8 & 17 & 0 \\
Leasing & 50 & 10 & 50 & 0 \\
\hline
\end{tabular}

The data on MADT is adjusted to a PDF, the values are right skewed; as in [12], the Lognormal, Gamma and Weibull functions were considered. All data were analyzed using STATGRAPHICS Centurion XVII.

To evaluate the goodness of fit between histogram and the PDF were used the Chi-Squared (CS) and Kolmogorov-Smirnov (KS) tests. All histograms are right skewed, the result shows that the Lognormal PDF can be used to represents the data distribution, in Table 2 MADT media and standard deviation in each group are shown. 
Table 2. PDF parameters per group.

\begin{tabular}{ll}
\hline Group & Distribution Parameters \\
\hline General & Media: $77,98 \mathrm{~km}$ \\
Private & Standard Deviation: $67,74 \mathrm{~km}$ \\
& Media: $56,54 \mathrm{~km}$ \\
Public & Standard Deviation: $58,98 \mathrm{~km}$ \\
Taxis & Media: $85,74 \mathrm{~km}$ \\
& Standard Deviation: $57,74 \mathrm{~km}$ \\
Leasing & Media: $153,81 \mathrm{~km}$ \\
& Standard Deviation: $103,9 \mathrm{~km}$ \\
\hline
\end{tabular}

It is possible to estimate a MADT representative value in each group using the Cumulative Distribution Function (CDF), the MADT at $85 \%$ of probability was selected as a criterion. This means that $85 \%$ of cars have a MADT equal or below this value.

For the private vehicles group, an $85 \%$ have a MADT below or equal to $95,2 \mathrm{~km}$ in a week, this is within the range of many EV in market. If a safety buffer of $25 \%$ of travel distance is considered, [10] to reduce the range anxiety, the necessary range will be $118 \mathrm{~km}$.

In the group of vehicles in public service, the MADT for $85 \%$ is below or equal to $133,7 \mathrm{~km}$ in a week. Considering a safety buffer of $25 \%$, the necessary range will be $166,25 \mathrm{~km}$, almost $50 \mathrm{~km}$ more than for private vehicles.

In the case of taxis, the MADT for $85 \%$ is $240,6 \mathrm{~km}$ in a week, and with safety buffer raises to $300 \mathrm{~km}$, it is normal to find that a taxi requires a longer range. The group Leasing has a MADT for $85 \%$ of $272 \mathrm{~km}$, or $340 \mathrm{~km}$ adding the safety buffer, the largest value among all.

The problem of conventional car replacement by an electric one is not simple. Given the limitations in range inherent to a BEV and its effect on driving habits, it is important to select BEVs in correspondence with an expected performance. The BEV's range is associated with battery capacity and vehicle size, number of seats, and with motor power and maximum speed, and overall, with car price.

In order to propose one or more BEV that can fulfill the requirements for each group, a database with technical parameters of more than 60 different BEV's models and brands was prepared. American, European, Korean, Japanese and Chinese BEV models manufactured from 2015 to 2020 were considered.

As it is known, the range in BEV is determined according to a given driving cycle. Normally, all models offer the range by NEDC and/or by WLTP, but none of this driving cycles reflects the reality of urban traffic correctly. The NEDC overestimate the range and the WLTP also gives range longer than real. Some cars give also a range by EPA, which consider the use of air-conditioned or heating, and combines city driving with highway driving, but even with this, it is beyond the real range. The fact is that the real range of a BEV depends also of driving style; a range by a driving cycle is useful only for comparison. Besides, Chinese automakers use to give only range by NEDC, or in some cases, by a special driving cycle CDC v1 (China Specific Drive Cycle for Emissions and Fuel Consumption test v1, shortly, China Driving Cycle v1), close to NEDC but even more relaxed.

The data on all BEV considered is in Table 3, was obtained from [21-23] and contrasted with other sources in the web. The author criterion is that the sources used are well completed and reliable. All prices are original and in USD, calculated as 0,14 USD per Chinese Yuan, 1,12 USD per Euro and 1,27 USD per British Pound, and will be used only as reference.

In order to make a correct comparison all cars should have the range by the same driving cycle. The range by EPA was chosen for comparison, considering that this driving standard takes both city and highway conditions, and is the lower among all. Taking into account that not all cars have range by EPA, the first problem to solve is to determinate if it is possible to infer an EPA range using the NEDC or WLTP cycles.

In the selection, 21 vehicles have information from the manufacturer about range according to EPA and WLTP, and 24 by EPA and NEDC. A linear regression model was adjusted between these two parameters in each case. Relation between range by EPA and range by WLTP can be treated as linear, following the Equation (1): 
$R_{E P A}=-62,9243+1,02656 \cdot R_{W L T P}$

$R_{E P A}, R_{W L T P}$

$\mathrm{R}=0,973$

$R^{2}=94,51 \%$

Std. error $=22,94$

MAbs. Error $=18,325$
Range by EPA and WLTP, km

Correlation coefficient

R-squared

standard error

Mean absolute error

And for range by EPA and NEDC, Equation (2):

$R_{E P A}=-62,9162+0,921356 \cdot R_{N E D C}$

$R_{E P A}, R_{N E D C}$

Range by EPA and WLTP, km

$\mathrm{R}=0.962$

Correlation coefficient

$R^{2}=92,61 \%$

R-squared

Std. error $=38,44$

MAbs. Error $=26,95$

standard error

Mean absolute error

As can be observed, there is a good linear correlation between range by EPA and range by WLTP or NEDC. The coefficient for the independent variable is close to 1 , and the constant is almost the same in both models. This means that to obtain the range by the EPA driving cycle, the range by WLTP or NEDC have to be reduced in $62,9 \mathrm{~km}$, approximately. These expression should be used carefully but represents a guide in order to make a better BEV range prediction by EPA.

Figure 1 shows the two regression models. Internal lines at both sides of the model represent the confidence interval for the mean value of $R_{E P A}$ at a value of $R_{W L T P}$ or $R_{\text {NEDC }}$ respectively. External lines represent the limits for new prediction based on the model. As the Mean Absolute Error in the model of WLTP is slightly lower than model of NEDC, in the case that a vehicle has these two ranges, the range by WLTP is the favorite to calculate range by EPA. With these equations, the range according to EPA was completed for all vehicles.
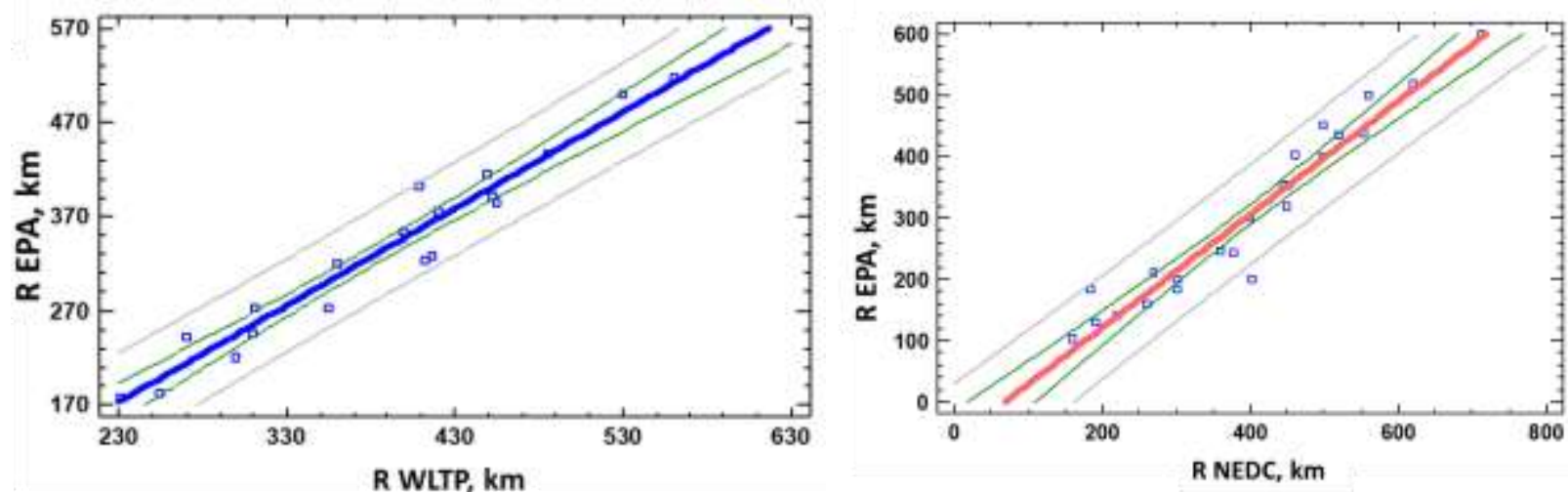

Figure 1. Regression models for range by EPA.

In Table 3 these values are in the column EPA in bolded numbers, 17 in total. 
Table 3. Electric Vehicle Technical Information.

\begin{tabular}{|c|c|c|c|c|c|c|}
\hline Brand and model & Year & Mass (kg) & $\begin{array}{l}\text { Battery } \\
\text { (kWh) }\end{array}$ & Capacity & EPA range $(\mathrm{km})$ & Price (USD) \\
\hline e.GO Life 20 & 2019 & 880 & 14,5 & & 40 & 17900 \\
\hline e.GO Life 40 & 2019 & 1170 & 17,5 & & 53 & 19660 \\
\hline Volkswagen e-up! & 2019 & 1229 & 18,7 & & 82 & 26600 \\
\hline e.GO Life 60 & 2019 & 1210 & 23,5 & & 86 & 21470 \\
\hline JAC i EV 4 & 2017 & 1260 & 35,6 & & 90 & 19110 \\
\hline Smart fortwo III cabrio & 2017 & 1085 & 17,6 & & 102 & \\
\hline Renault Fluence ZE & 2015 & 1605 & 22 & & 110 & 22200 \\
\hline BAIC ES 210 EV Senova & 2015 & 1760 & 38 & & 121 & 48566 \\
\hline BAIC EX 200 EV & 2016 & 1360 & 30,4 & & 121 & 28960 \\
\hline Renault Twingo ZE Life & 2020 & 1112 & 22 & & 122 & 23000 \\
\hline SAIC Roewe E50 EV & 2020 & 1080 & 18 & & 122 & 26300 \\
\hline Changan NIOU II EV & 2019 & 795 & 21,3 & & 126 & 44800 \\
\hline BMW i3 & 2016 & 1195 & 22 & & 130 & 27000 \\
\hline Chevrolet Spark EV & 2016 & 1300 & 18,4 & & 131 & 25120 \\
\hline Volkswagen e-golf SEL & 2016 & 1538 & 24,2 & & 133 & 37345 \\
\hline Fiat $500 \mathrm{e}$ & 2019 & 1355 & 24 & & 135 & 33460 \\
\hline Honda e 35.5 & 2019 & 1537 & 35,5 & & 142 & 32000 \\
\hline SAIC Maxus EV80 LDV & 2019 & 2440 & 71 & & 149 & 35574 \\
\hline Changhe $x 5$ e EV 168 & 2017 & 1070 & 22 & & 160 & 16739 \\
\hline Chery eQ EV & 2018 & 1128 & 22,3 & & 168 & 14277 \\
\hline Mini Cooper SE Nivel I & 2020 & 1365 & 32,6 & & 177 & 30750 \\
\hline BMW i3 & 2018 & 1245 & 33,2 & & 183 & ------- \\
\hline Ford Focus & 2018 & 1651 & 33,5 & & 184 & 29120 \\
\hline Great wall C30 & 2016 & 1390 & 37 & & 190 & 19570 \\
\hline Renault Zoe R90 & 2017 & 1480 & 45,6 & & 200 & 33600 \\
\hline Volkswagen e-Golf SE & 2019 & 1615 & 35,8 & & 201 & 31895 \\
\hline SEAT Mii & 2020 & 1235 & 36,8 & & 204 & 23300 \\
\hline MG ZS EV excitE & 2019 & 1502 & 44,5 & & 207 & 35900 \\
\hline Changhe EV5 long range & 2020 & 1560 & 43 & & 210 & 16665 \\
\hline Renault Zoe Q90 & 2019 & 1480 & 45,61 & & 220 & 37900 \\
\hline KIA e Niro 39 & 2019 & 1593 & 39,2 & & 221 & 42000 \\
\hline Nissan Leaf S & 2018 & 1557 & 40 & & 243 & 29900 \\
\hline Nissan Leaf SV Plus & 2019 & 1591 & 40 & & 243 & 36300 \\
\hline BMW I3s & 2019 & 1345 & 42,2 & & 246 & 44500 \\
\hline BMW i3s & 2020 & 1379 & 42 & & 246 & 56500 \\
\hline Renault Zoe R135 & 2020 & 1468 & 55 & & 272 & ------- \\
\hline Hyundai IONIQ electric & 2020 & 1527 & 38,3 & & 273 & ------- \\
\hline Opel Corsa-e First ed & 2020 & 1530 & 50 & & 276 & 37100 \\
\hline BYD e6 & 2018 & 2450 & 91 & & 299 & 52000 \\
\hline JAC iEV A60 & 2019 & 1990 & 68 & & 310 & 27584 \\
\hline BAIC X55 II Senova & 2019 & 1770 & 61,8 & & 319 & 16800 \\
\hline Porsche Taycan Turbo S & 2020 & 2295 & 93,4 & & 324 & 187000 \\
\hline Audi e- tron 55 quattro & 2019 & 2490 & 95 & & 328 & 91400 \\
\hline Nissan Leaf SL Plus & 2019 & 1748 & 62 & & 346 & 42500 \\
\hline Denza 500 EV & 2017 & 2120 & 70 & & 353 & 52000 \\
\hline Mercedes-Benz EQC 400 4MATIC & 2020 & 2495 & 80 & & 354 & 82700 \\
\hline Jaguar I-Pace & 2020 & 2170 & 90 & & 376 & 69500 \\
\hline Chevrolet Bolt EV & 2019 & 1625 & 60 & & 383 & 37945 \\
\hline KIA e Niro 64 & 2019 & 1748 & 64 & & 384 & 38500 \\
\hline Peugeot e-208 & 2019 & 1455 & 50 & & 390 & 31700 \\
\hline KIA Soul EV & 2020 & 1506 & 64 & & 391 & 47500 \\
\hline Audi e- Tron Sportback 50 Q & 2020 & 2445 & 71 & & 395 & 80625 \\
\hline Geely Emgrand EV 550 & 2019 & 1570 & 52 & & 400 & 32300 \\
\hline Tesla model 3 SR Plus RWD & 2019 & 1611 & 54 & & 402 & 39490 \\
\hline NIO ES6 80 & 2019 & 2290 & 84 & & 407 & 69170 \\
\hline Hyundai KONA electric $64 \mathrm{~kW}$ & 2019 & 1685 & 64 & & 415 & 36950 \\
\hline Chevrolet Bolt EV & 2020 & 1616 & 66 & & 416 & 37495 \\
\hline Tesla Model S Standard & 2019 & 2163 & & & 436 & 75000 \\
\hline Tesla Model X Performance SR & 2020 & 2604 & 100 & & 437 & 99990 \\
\hline Geely Geometry A & 2019 & 1650 & 61,9 & & 440 & 25250 \\
\hline
\end{tabular}


NIO ES8 EV7 LR

Tesla Model 3 Performance AWD

Tesla Model 3 long range

Tesla Model S long range
2020

2019

2020

2019
2425

1860

1847

2215

100
79,5
79,5
100

100

100
471

499

518

600
89665

56900

46900

79900

Once the data on range by EPA is completed, it is possible to analyze which BEV can be proposed as the most adequate for each group. Twelve models in Table 3 have a range between 120 and $160 \mathrm{~km}$ (considering the next group range), and could be used in group Private.

As can be seen, even models with a similar range have a very different price, motor power, efficiency and battery capacity; price is strongly linked with battery capacity. With the exception of the Changan NIOU II EV, which is a small two seats car, the rest adjusts to group requirements. Another factor to include is the efficiency, but not all models have data according to the same driving cycle, and it was impossible to establish some correlation between efficiency by NEDC, WLTP and EPA (not shown in Table 3). The most rigorous evaluation would be done using EPA values but only 5 models offer this information. Nevertheless, is possible to compare in base a NEDC and WLTP cycles, results in both are similar.

As China produces many models of BEV with competitive prices, a Chinese model will always be selected in each group. The price, range, efficiency and a comparable performance are the main parameters for selection, car type can be different. So, for further analysis, SAIC Roewe E50 EV and Renault Twingo ZE Life will be chosen as possible selection in group Private. Both are similar in weight, dimensions and performance. BMW i3 has a good efficiency by EPA, but price is higher than Twingo's.

Regarding the group Public, and taking the interval between 160 and $240 \mathrm{~km}$, the Great Wall C30 and the well-known Renault Zoe R90, shall be selected for further analysis, considering that range is similar in both models.

For the group Taxis, the Peugeot e-208 and Geely Emgrand EV 500 are the selection, and in group Leasing were selected Geely Emgrand EV and Renault Fluence EV

Normally, cost comparison between EV and ICEV are made using a TCO analysis. TCO analysis are frequently divided in consumer oriented or society oriented [15]. Price, electricity and fuel cost, maintenance cost, subsidies, $\mathrm{CO} 2$ tax, etc., are considered during the vehicle expected life. But all these items varies from one country to another, for example, subsidy policy varies among countries, maintenance cost still undefined for BEV and depends on vehicle mileage and national conditions.

Car market in Cuba is very limited and until now, no BEV have been sold to private owners, so, it is impossible to establish a real sale price; there is no information about possible subsidies, financing facilities and resale prices for EV neither. In order to make a preliminary analysis of ICEV replacement by BEV, the usual TCO will not be considered, instead, a Total Cost of Operation (TCOp) will be calculated. This TCOp allows evaluation of the impact on national economy of future transport electrification. The TCOp is defined in Equation (3):

$$
T C O_{p}=\left[C_{p}+C_{t a x}+C_{I N F}\right]+\left[C_{i n s}+M \& R \cdot C_{m r}^{I C E V}+A D M \cdot \eta_{e l} \cdot C_{e l} \cdot \frac{330}{100}\right] N
$$

$C_{p}$

$C_{\text {tax }}=C_{p} \cdot T$

$C_{p}$

$T$

$C_{I N F}$

$C_{\text {ins }}=C_{p} \cdot I \cdot N$

$N$

$M \& R$

$C_{m r}^{I C E V}$

$A D M$

$\eta_{e l}$

$C_{e l}$
Vehicle price, USD

Import tax, USD

Initial price, USD

Tax coefficient, 0,1

Charging Station cost, USD

Insurance Policy, USD

Insurance coefficient, 0,1

years

Maintenance and repair coefficient, 0,25

Maintenance and repair average annual cost of ICEV, USD

Average daily mileage, $\mathrm{km}$

Specific energy consumption , kWh / $100 \mathrm{~km}$

Electricity cost, USD / kWh 
The insurance cost is related to vehicle price and is constant during vehicle life and depends only on initial price. The initial price was taken from public sources in the web. The infrastructure cost is related to all facilities needed to charge an EV; this includes a wall box and accessories. For the Private group, it will be assumed a 3,2 kW system, and for the Public, Taxis and Leasing, a $7 \mathrm{~kW}$ unit. Prices, models and suppliers are very diverse, an example is [24] with more than 2000 products. The price of a 3,2 kW system is assumed as 200 USD, and for a $7 \mathrm{~kW}$ unit is 300 USD.

The energy cost is related to average yearly mileage, vehicle efficiency, years in use and electricity price, in this article, it is assumed that a car works 330 days a year. In Cuba, electricity is produced mainly in thermal plants; average cost is $0,165 \mathrm{USD} / \mathrm{kWh}$.

The period of use of a car, including BEV depends on the country and owner's habits, in Cuba it is normal to use an automobile for more than 15, and even 20 years, here it will be supposed no battery replacement, and will be limited to 10 years. The ADM is assumed as the mean value of MADT in each group, Table 2.

The maintenance and repair cost are determined as a percentage of maintenance and repair cost of an ICEV. For a BEV this cost is lower compared to an ICEV, several authors give values from 44\% [25], 52\% [17], $70 \%$ [26] to almost $80 \%$ [19]. In Cuba, labor cost is smaller than in Europe and America, the author consulted several workshops and the national companies using BEV, and the criterion is that even a $25 \%$ is highly enough to represent this share of cost for a BEV, including parts cost; and will be constant in all vehicle life. The average ICEV maintenance and repair cost per year was obtained from the survey, and result in 538 USD for private cars, 548 USD for public cars and 647 USD for taxis and leasing. Considering Cuba conditions, these values are close to the proposed in [27].

The most of EV manufacturers offers a battery warranty period of 8 years or $100000 \mathrm{~km}$ as an average, but battery duration can be longer, new batteries have demonstrated an improved technology and there is not enough experience at the moment to establish with certainty the battery life. Some authors consider only $75000 \mathrm{~km}$ of battery life [15], but others give near to $500000 \mathrm{~km}$ [19]. The battery replacement will not be considered in the 10 years period.

It is easy to see that TCOp follows the equation of a straight line, with intercept $\left[\boldsymbol{C}_{\boldsymbol{p}}+\boldsymbol{C}_{\boldsymbol{t a x}}+\boldsymbol{C}_{I N F}\right]$ and slope $\left[C_{i n s}+M \& R \cdot C_{m r}^{I C E V}+A D M \cdot \eta_{e l} \cdot C_{e l} \cdot \frac{330}{100}\right]$.

The TCOp for an ICEV is similar, but without $\mathrm{C}_{\mathbb{I N F}}$, and considering the specific fuel consumption $\mathrm{g}_{\mathrm{esp}}$ in $\mathrm{L} / 100$ $\mathrm{km}$, and $\boldsymbol{C}_{\text {fuel }}$ as the fuel cost, equation (4).

$\mathrm{TCO}_{p}=\left[C_{p}+C_{t a x}\right]+\left[C_{\text {ins }}+M \& R \cdot C_{m r}^{I C E V}+A D M \cdot g_{\text {esp }} \cdot C_{f u e l} \cdot \frac{330}{100}\right] N$

In the literature, many TCO analysis compare a BEV with an ICEV of popular brands in the same market. The BEVs in this case, are compared against Chinese Geely CK [21], Geely Emgrand EC9 [28], French Renault Fluence [29] or Lattitude [30] and Russian Lada Vesta [30]. The Geely CK is widely used by private owners and the Lada Vesta in public and taxi services, the Renault Lattitude and Fluence; and Geely Emgrand EC9 are used in leasing. General information for these vehicles is in Table 4. As the Lada Vesta appears in two groups, a T was added for Taxis group. The last column shows gasoline prices $\mathrm{C}_{\text {fuel, }}$, slightly higher for private owners. The Table 4 shows the specific fuel consumption (equivalent) for BEV, only for illustration. 
Table 4. BEV and ICEV data.

\begin{tabular}{|c|c|c|c|c|c|c|c|c|c|}
\hline Model & Price & Import tax & insurance & Maint. and Repair. & $\eta_{\mathrm{el}}$ & gesp & ADM & kWh price & Fuel price \\
\hline Private & USD & USD & USD & USD & $\mathrm{kWh} / 100 \mathrm{~km}$ & $\mathrm{~L} / 100 \mathrm{~km}$ & $\mathrm{~km} / \mathrm{day}$ & USD/kWh & USD/L \\
\hline Renault Twingo ZE Life & 23000 & 2300 & 1610 & 134,5 & 16,3 & 1,84 & 56 & 0,165 & 1.09 \\
\hline SAIC Roewe E50 EV & 26300 & 2630 & 1841 & 134,5 & 16,5 & 1,42 & 56 & 0,165 & 1.09 \\
\hline $\begin{array}{l}\text { Geely CK } \\
\text { Public }\end{array}$ & 7042 & 704 & 493 & 538 & & 6.5 & 56 & & 1,20 \\
\hline Gran Muralla C30 & 19670 & 1967 & 1377 & 137 & 14,76 & 1,66 & 85 & 0,165 & \\
\hline Renault Zoe R90 & 33600 & 3360 & 2352 & 137 & 16,8 & 1,49 & 85 & 0,165 & \\
\hline $\begin{array}{l}\text { LADA Vesta } \\
\text { Taxis }\end{array}$ & 8800 & 880 & 616 & 548 & & 7.1 & 86 & & 1,15 \\
\hline Peugeot e-208 & 31700 & 3170 & 2219 & 161,75 & 14,7 & 1,66 & 154 & 0,165 & 1.09 \\
\hline Geely Emgrand EV500 & 19300 & 1930 & 1351 & 161,75 & 13,2 & 1,78 & 154 & 0,165 & 1.09 \\
\hline $\begin{array}{l}\text { LADA Vesta T } \\
\text { Leasing }\end{array}$ & 8800 & 880 & 616 & 647 & & 7.1 & 154 & & 1,15 \\
\hline Renault Latitude & 23900 & 2390 & 1673 & 647 & & 8,3 & 210 & & 1 \\
\hline Renault Fluence & 16000 & 1600 & 1120 & 647 & & 6,8 & 210 & & 1,2 \\
\hline Geely Emgrand EC-9 & 21140 & 2114 & 1480 & 647 & & 11 & 210 & & 1,2 \\
\hline Renault Fluence ZE & 22200 & 2220 & 1554 & 161,75 & 14 & 1.65 & 210 & 0,165 & \\
\hline Geely Emgrand EV500 R & 19300 & 1930 & 1351 & 161,75 & 13,2 & 1.78 & 210 & 0,165 & \\
\hline
\end{tabular}




\section{RESULTS}

The results of TCOp in 10 years of use for each group selected are shown below. Two possible scenarios are analyzed: first, with the use of electricity from thermal plants; second, with electricity only from renewable sources, as the photovoltaic panels.

In the first case, Figure 2, no BEV compete with an ICEV for private use, the Geely CK is far below both $B E V$. This is determined by two factors: the higher price of a BEV places the starting point (or intercept) well above from the same point for the Geely CK; and the Geely CK has a low specific fuel consumption. A strong subsidy could make one of the BEV competes with Geely CK's TCOp.

In the case of public service, the Great Wall C30 is better than Lada Vesta at the 9th year of use. And in the taxis service, the Geely Emgrand is also better than Lada Vesta, but from the 4th year. A larger ADM in both cases, compared with private group is decisive. Finally, in the leasing group, both the Renault Fluence EV and Geely Emgrand EV500, have a lower TCOp than their similar ICEVs almost from the beginning of use.
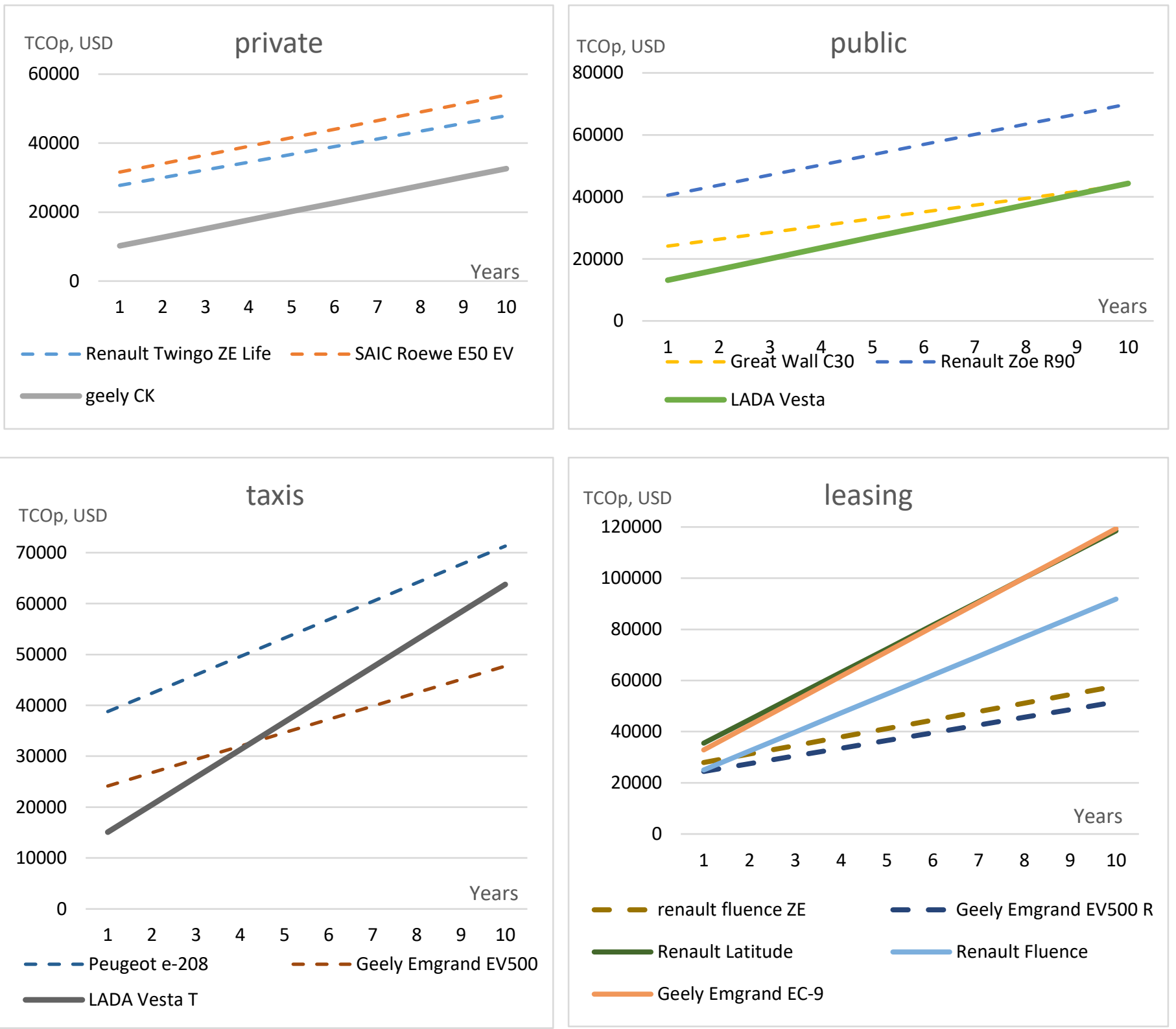

Figure 2. TCOp with electricity from thermal plant.

The influence of the ADM in each group is evident: the longer the distances travelled per day, the bigger the savings in fuel; a higher mileage makes the BEV more competitive against an ICEV, in spite of a higher initial purchase price.

If electricity comes from renewable sources, has a price of $0,07 \mathrm{USD} / \mathrm{kWh}$, standard price of electric energy from solar sources in Cuba. The scenery of solar energy to power a BEV considers the solar plant Brazilian Archives of Biology and Technology. Vol.64: e21210290, 2021 www.scielo.br/babt 
integrated to the grid. The case of solar chargers for individual use represents an extra expenditure to BEV proprietaries, and was not considered. For public use this is a very attractive possibility, several BEV can use the charging station and this reduces cost. Besides, during daytime the station can sell electricity to the grid and use grid to charge at night. The results are shown in Figure 3, in private group is similar, both BEVs are over the Geely CK all the time. For the public use, now the Great Wall C30 is better at the 7th year of use, and in the taxis service, the Geely Emgrand EV still better than an ICEV. For the leasing service, a BEV will be the best selection from the very beginning. The lower cost of electricity reinforces the effect of a larger ADM in this result.
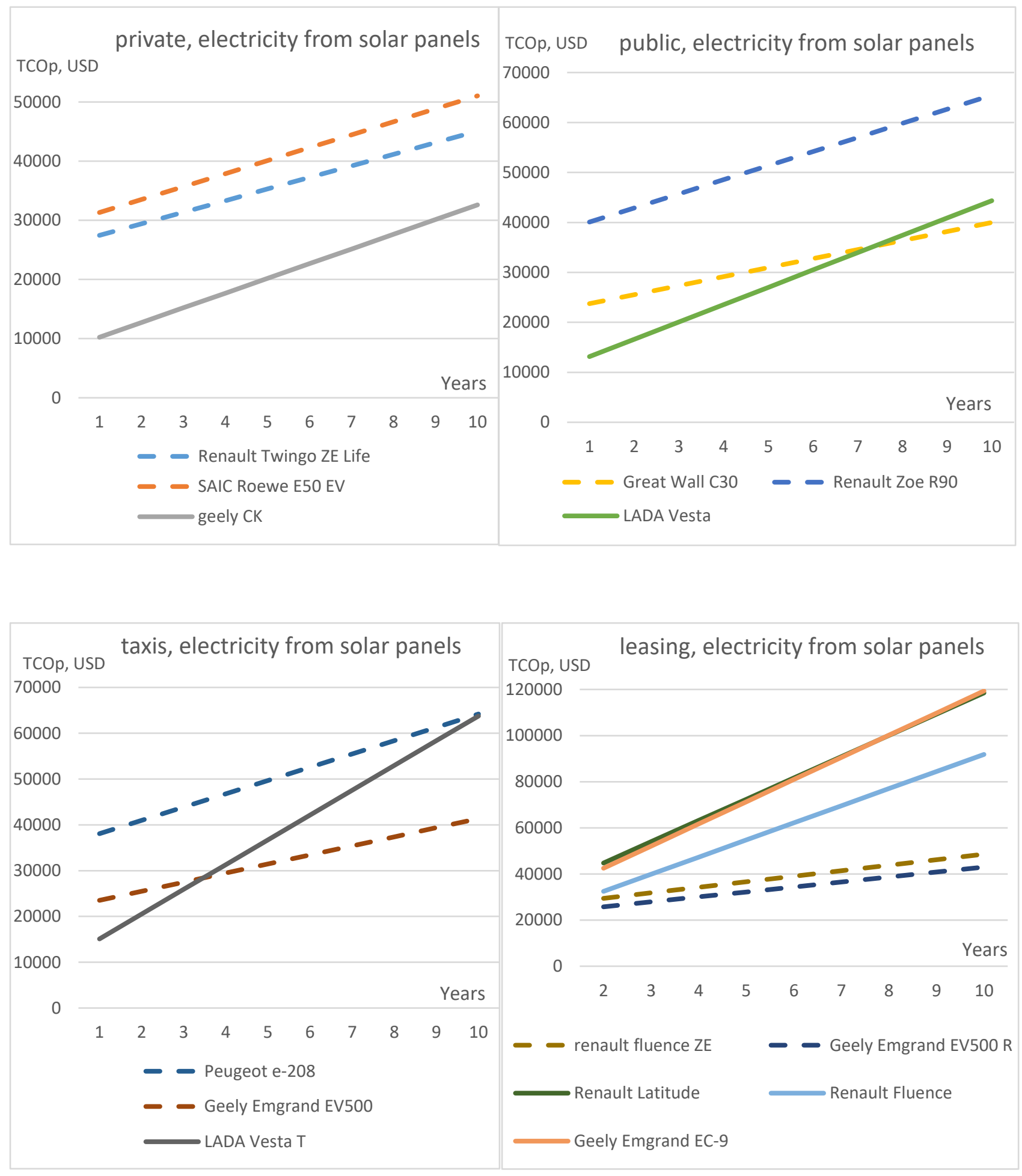

Figure 3. TCOp with electricity from solar panels.

A well-conceived business model can be useful for the electric mobility introduction. For example, the private owners and public companies can be invited to change their ICEV (considering the ICEV is in good 
shape) by a BEV, taking into account that this ICEV could be then disassembled, and some pieces and components sold as replacements, in a market with a lot of old cars and shortage of these spare parts. This can contribute to, or play the role of a subsidy in Cuban conditions. In addition, the business model can consider the battery leasing as an alternative to reduce initial prices of BEV, either separated or combined with car exchange.

Finally, the charging network is crucial for the acceptance of electric vehicle. A study on traffic patterns is necessary to define location and distance between charging points in the city. At the moment, the authorities have only a general idea on this issue, it is necessary to move forward with more research and resolution, in order to make BEV adoption acceptable and sustainable.

\section{CONCLUSION}

The possibility of introduction of the BEV in Cuban transport system have been analyzed using a TCOp toll and the MADT as indicator. A sample of 376 vehicles was divided in four groups, based on car use. The MADT in each groups was adjusted to a PDF. The Lognormal distribution fits to data in all cases. Using a CDF analysis, the MADT for $85 \%$ of cars in each group is used as BEV's minimum range required to satisfy group requirements. This minimum range is different in each group, for private owners it is the lowest.

For the selection of a BEV, a database was prepared, and the range by EPA standards was considered as the best criterion. However, information about range is incomplete in some car models. In order to complete data, a regression model between range by EPA and range by NEDC or WLTP was obtained. Using the database, two models of BEV were proposed as possible candidates in each group. These BEV are then compared against an ICEV present in Cuban market.

The comparison is based on the results of a Total Cost of Operation analysis, which includes cost of purchase, insurance, maintenance and repair cost, fuel or electricity cost, etc. The main component of TCOp for BEV is the cost of purchase, and for ICEV is the fuel cost. TCOp was evaluated for 10 years of use.

For the private use, no BEV competes with an ICEV. Only with some help from the government can a BEV be competitive respect to an ICEV. Not only the Roewe, no any other BEV in Table 3 can be compared with a very cheap option as the Geely CK is. For the public service, one of the proposed BEV is competitive after nine years of use, and for taxis, one model compete after four years. In the leasing service, both BEV are competitive very fast.

If the solar energy is used as the only source to charge batteries, then in the public and taxis group, the BEV time to match TCOp of ICEV is reduced in some years, but in the private group remains over the ICEV.

An appropriate business model can be very useful to help the BEV introduction, this model can consider a battery leasing; or an ICEV exchange by a BEV instead a subsidy, or both. A subsidy is very unlikely in Cuban present conditions.

More research are needed regarding economic impact of electric vehicles introduction. The use of renewable energies to recharge batteries needs special attention, as it can be a key factor in lowering the total cost of BEV.

Funding: "This research received no external funding".

Conflicts of Interest: "The author declare no conflict of interest."

\section{REFERENCES}

1. IEA. Global EV Outlook 2019. [Internet] Electric Vehicle Initiative, 2019. 232 p.

2. ONEI. TRANSPORTE: INDICADORES SELECCIONADOS. [Internet] Cuba: Centro de Gestión de la Información Económica, Social y Medioambiental, 2018. 12 p.

3. Prices GP. Global Petrol Prices [internet]. 2020 [10/feb/2020]. Available from: https://es.globalpetrolprices.com/diesel_prices/.

4. López AC. Determinación de los factores de equivalencia vehicular en las principales carreteras rurales de dos carriles que acceden a la ciudad de Santa Clara. [Tesis de graduación]. Santa Clara: Universidad Central "Marta Abreu" de Las Villas; 2017.

5. Melliger MA, Vliet Ov, Liimatainen $\mathrm{H}$. Anxiety vs reality - Sufficiency of battery electric vehicle range in Switzerland and Finland. Transportation Research Part D. 2018;65:5. doi: 10.1016/j.trd.2018.08.011. 101-5

6. Needell ZA, McNerney J, Chang MT, Trancik JE. Potential for widespread electrification of personal vehicle travel in the United States. Nature Energy. 2016;1(9):9b. doi: 10.1038/nenergy.2016.112. 16112-9b

7. Shi X, Pan J, Wang $\mathrm{H}$, Cai $\mathrm{H}$. Battery Electric Vehicles: What is the Minimum Range Required? Energy 2018;2018:15. doi: 10.1016/j.energy.2018.10.056. 1-15 
8. Franke T, F.Krems J. What drives range preferences in electric vehicle users? Transport Policy. 2013(30):7. doi: 10.1016/j.tranpol.2013.07.005. 56-7

9. Dimitropoulos A, Rietveld P, Ommeren JV. Consumer valuation of changes in driving range: A meta-analysis. Transportation Research Part A. 2013(55):14. doi: 10.1016/j.tra.2013.08.001. 27-14

10. Yuan Q, Hao W, Su H, Bing G, Gui X, Safikhani A. Investigation on Range Anxiety and Safety Buffer of Battery Electric Vehicle Drivers. Journal of Advanced Transportation. 2018;2018:12. doi: 10.1155/2018/8301209. 1-12

11. Pearre NS, Kempton W, Guensler RL, Elango VV. Electric vehicles: How much range is required for a day's driving? Transportation Research Part C. 2011(19):14. doi: 10.1016/j.trc.2010.12.010. 1171-14

12. Plötz P, Jakobsson N, Sprei F. On the distribution of individual daily driving distances. Transportation Research Part B. 2017(101):15. doi: 10.1016/j.trb.2017.04.008. 213-15

13. Bastian $\mathrm{C}$, Kagerbauer M, Vortisch P, Wirges J. Market potential for electric vehicles from a travel behavior perspective. 91st Annual Meeting of theTransportation Research Board; sept. 2012; Washington, DC2012.

14. Yang J, Dong J, Zhang Q, Liu Z, Wang W. An Investigation of Battery Electric Vehicle Driving and Charging Behaviors Using Vehicle Usage Data Collected in Shanghai, China. Journal of the Transportation Research Board. 2018;1(11):11. doi: 10.1177/0361198118759015. 1-11

15. Lebeau K, Lebeau P, Macharis C, Mierlo JV. How expensive are electric vehicles? A total cost of ownership analysis. EVS27; 17-20 Nov.; Barcelona, Spain. Spain2013. p. 12.

16. Breetza HL, Salonb D. Do electric vehicles need subsidies? A comparison of ownership costs for conventional, hybrid, and electric vehicles. TE3 Conference; 25 sept. 2017. USA2017. p. 12.

17. Logtenberg R, Pawley J, Saxifrage B. Comparing Fuel and Maintenance Costs of Electric and Gas Powered Vehicles in Canada. [Internet] 2 Degrees Institute, 2018. 23 p.

18. Raustad R. Electric Vehicle Life Cycle Cost Analysis. [Internet] USA: Electric Vehicle Transportation Center, 2017 Contract No.: FSEC-CR-2053-17. 32 p.

19. Pröpfe B, Redelbach M, Santini DJ, Friedrich H. Cost analysis of Plug-in Hybrid Electric Vehicles including Maintenance \& Repair Costs and Resale Values. International Battery, Hybrid and Fuel Cell Electric Vehicle Symposium; 6-9/5/2012; Los Angeles, California: WEVJ; 2012. p. 10.

20. Alexander M, Davis M. TCO model for current Plug-in Electric Vehicles. [Internet] USA: Electric Power Research Institute 2013 3002001728. 80 p.

21. chinaautoweb. ChinaAutoWeb [internet]. 2020 [15/7/2020]. Available from: http://chinaautoweb.com/carmodels/.

22. EVSpecification [internet]. 2020 [24/enero/2020]. Available from: https://www.evspecifications.com/.

23. wattev2buy. wattev2buy [internet]. 2020 [15/7/2020]. Available from: https://wattev2buy.com.

24. alibaba. Wallbox Ev- Wallbox Ev Manufacturers, Suppliers and Exporters on Alibaba.com [internet]. 2020 [8/15/2020]. Available from: https://www.alibaba.com/premium/_wallbox_ev/.

25. Liu X, NingWang, Dong D, Fang T. Modeling total lifecycle ownership cost of battery electric vehicle based on urban traffic data in China. Advances in Mechanical Engineering. 2019;11(5):18. doi: 10.1177/1687814019851997. 1-18

26. Bakker D. Battery Electric Vehicles Performance, CO2 emissions, lifecycle costs and advanced battery technology development [Master Degree]. Netherlands: Copernicus institute University of Utrecht 2010.

27. Mitropoulos LK, Prevedouros PD, Kopelias P. Total cost of ownership and externalities of conventional, hybrid and electric vehicle. Transportation Research Procedia. 2016;24:267-74. doi: 10.1016/j.trpro.2017.05.117. 26774

28. Chinaautoweb. Geely emgrand EC9 [internet]. China2020 [2/feb/2020]. Available from: http://chinaautoweb.com/car-models/geely-emgrand-ec8-sedan/.

29. autodata. Renault Fluence (facelift 2012) Technical specs, data, fuel consumption, Dimensions [internet]. 2020 [28/agosto/2020]. Available from: https://www.auto-data.net/en/renault-fluence-facelift-2012-1.6-energy-dci$130 \mathrm{hp}-18018$.

30. LADA. Vehicle specifications Vesta sedan [internet]. 2020 [20/sep/2020]. Available from: https://www.lada.ru/en/cars/vesta/sedan/tth.html. 